\title{
Study of magnetic silk fibroin nanoparticles for massage-like transdermal drug delivery
}

\author{
This article was published in the following Dove Press journal: \\ International Journal of Nanomedicine \\ 21 July 2015 \\ Number of times this article has been viewed
}

\author{
Ai-Zheng Chen ${ }^{1-3}$ \\ Lin-Qing Chen' \\ Shi-Bin Wang ${ }^{1-3}$ \\ Ya-Qiong Wang' \\ Jun-Zhe Zha' \\ 'College of Chemical Engineering, \\ ${ }^{2}$ Institute of Pharmaceutical \\ Engineering, ${ }^{3}$ Institute of Biomaterials \\ and Tissue Engineering, Huaqiao \\ University, Xiamen, People's Republic \\ of China
}

\begin{abstract}
A synergistic approach by the combination of magnetic nanoparticles with an alternating magnetic field for transdermal drug delivery was investigated. Methotrexate-loaded silk fibroin magnetic nanoparticles were prepared using suspension-enhanced dispersion by supercritical $\mathrm{CO}_{2}$. The physiochemical properties of the magnetic nanoparticles were characterized. In vitro studies on drug permeation across skin were performed under different magnetic fields in comparison with passive diffusion. The permeation flux enhancement factor was found to increase under a stationary magnetic field, while an alternating magnetic field enhanced drug permeation more effectively; the combination of stationary and alternating magnetic fields, which has a massage-like effect on the skin, achieved the best result. The mechanistic studies using attenuated total reflection Fourier-transform infrared spectroscopy demonstrate that an alternating magnetic field can change the ordered structure of the stratum corneum lipid bilayers from the gel to the lipid-crystalline state, which can increase the fluidity of the stratum corneum lipids, thus enhancing skin penetration. Compared with the other groups, the fluorescence signal with a bigger area detected in deeper regions of the skin also reveals that the simulated massage could enhance the drug permeation across the skin by increasing the follicular transport. The combination of magnetic nanoparticles with stationary/alternating magnetic fields has potential for effective massage-like transdermal drug delivery.
\end{abstract}

Keywords: magnetic nanoparticles, magnetophoresis, supercritical fluid, alternating magnetic field, methotrexate

\section{Introduction}

Transdermal drug-delivery systems have attracted increasing attention due to their significant potential in avoiding the hepatic first-pass metabolism; maintaining a constant and prolonged drug level; providing for a local target; and offering a convenient method of administration. ${ }^{1}$ However, the transdermal permeation of drugs is limited by the stratum corneum (SC), which functions as a barrier. Therefore, several permeation enhancement techniques have been explored to improve the transdermal penetration of drugs with poor permeation. ${ }^{2-6}$

Nanoparticles as noninvasive carriers have been widely adopted to improve the skin permeation of drugs. ${ }^{7-9}$ Although polymer nanoparticles have shown great potential in skin delivery, they cannot penetrate into the SC but accumulate on the skin surface, in furrows and hair follicles, thus limiting their advantages in percutaneous delivery. ${ }^{10}$ Therefore, strategies of combining polymer nanoparticles with active enhancement techniques for improving transdermal drug permeation have been investigated. ${ }^{11-13}$

Active strategies for enhancing drug permeation include iontophoresis, electroporation, ultrasound, and microneedle pretreatment. ${ }^{14-17}$ To some extent, these enhancement approaches can promote percutaneous drug penetration. However, there are 
some problems, such as the skin inflammation induced by microneedles remaining in the skin, and the damage caused by the breakdown of skin structure during electroporating. ${ }^{2}$ Magnetophoresis is an effective method for enhancing drug permeation across the SC under a magnetic field. Murthy ${ }^{18}$ and Murthy et a ${ }^{19}$ have applied a magnetic field to enhance the transdermal permeation of diamagnetic molecules such as salbutamol sulfate and benzoic acid. These studies involved the use of stationary permanent magnets to enhance the skin permeation of diamagnetic drugs, which would respond to the magnetic field according to magnetokinesis. However, since most drug molecules have no magnetic properties, we aimed to embed the drugs with magnetic particles to endow the drug with magnetic property, and then utilize the magnetic particles which could be used as a magnetic drug carrier to deliver drug molecules into the skin.

Furthermore, a pulsed electromagnetic field has been utilized to enhance the permeation of substances through the skin. It is believed that the interaction between a pulsed electromagnetic field and the skin could enhance transdermal drug delivery, ${ }^{20,21}$ and an electromagnetic field has been shown to induce a change in structures of keratinocytes. ${ }^{22}$ Recent developments have also confirmed that the hair follicles play a significant role in transdermal permeation and that the application of massage has a positive effect in follicular penetration. ${ }^{23-26}$ Lademann et $\mathrm{al}^{27}$ discovered that mechanical massage could result in a much deeper penetration of nanoparticles into the hair follicles than was the case without massage. It was assumed that with massage, the movement of hairs acted as a pump mechanism, pushing the nanoparticles more deeply into the hair follicles. It has also been demonstrated that the application of massage could stimulate the physiological movement of hairs. ${ }^{28}$

Thus, we proposed a synergistic approach by the incorporation of magnetic nanoparticles with an alternating magnetic field for transdermal drug delivery. We hypothesized that an alternating magnetic field influences both the ordered structure of the SC lipid bilayers and the movement of magnetic nanoparticles in the epidermis, simulating massage, which increases follicular transport and enhances drug permeation.

Silk fibroin (SF) obtained from cocoons is believed to be biocompatible and nontoxic to human skin. It is used as an active ingredient of cosmetics and biopharmaceutics because of its water-retaining, skin-adhesive, and anti-inflammatory properties. ${ }^{29-31}$ Suspension-enhanced dispersion by supercritical $\mathrm{CO}_{2}$ (SpEDS) has been used in our lab to prepare composite microparticles, since it can effectively reduce the residual solvent and control the particle distribution under mild conditions..$^{32,33}$
Methotrexate (MTX) is an antifolate class of antineoplastic agent which is used for the treatment of psoriasis and rheumatoid arthritis at low doses, and leukemia at high doses. ${ }^{34-36}$ The systemic use of this drug causes numerous side effects, such as hepatic toxicity, thrombocytopenia, anemia, fatigue, and so on. ${ }^{37}$ Topical delivery of MTX would be preferable and beneficial to reduce its side effects. However, a disappointing result has been reported on the insufficient percutaneous absorption of MTX. A major problem is that the drug is mostly in dissociated form at physiological $\mathrm{pH}$, thus limiting its capacity for passive diffusion. ${ }^{38}$ Iontophoresis and penetration enhancers have been used to increase the permeability of MTX. ${ }^{39,40}$ However, iontophoretic administration caused irreversible damage of skin and some penetration enhancers such as surfactants-induced skin irritation.

Therefore, in the present study, using MTX as a drug model, we attempted to prepare the MTX-loaded magnetic $\mathrm{SF}$ (MTX-Fe $\mathrm{O}_{4}$-SF) nanoparticles by SpEDS, and then use these nanoparticles as transdermal drug carriers to examine the penetration effect of drugs under an alternating magnetic field by detecting the accumulation of permeated drugs using high-performance liquid chromatography (HPLC). In addition, confocal laser scanning microscopy (CLSM) and attenuated total reflection Fourier-transform infrared spectroscopy (ATR-FTIR) were conducted to investigate the preliminary mechanism of permeation enhancement of an alternating magnetic field.

\section{Experimental section Materials}

Magnetic fluid which contains $\mathrm{Fe}_{3} \mathrm{O}_{4}$ nanoparticles with a mean size of approximately 10-30 nm was purchased from the Maanshan Jinke Powder Engineering Co., Ltd. (Maanshan, People's Republic of China). Silk powder was purchased from Huzhou Xintiansi Biotech Co., Ltd. (Huzhou, People's Republic of China). MTX with a purity of $99.9 \%$ was purchased from Surui Pharmaceutical Co., Ltd. (Suzhou, People's Republic of China). Fluorescein isothiocyanate (FITC) was provided by Sangon Biotech Co., Ltd. (Shanghai, People's Republic of China). Dichloromethane (DCM) (99.8\% purity) was purchased from the Sinopharm Chemical Reagent Co., Ltd. (Shanghai, People's Republic of China). 1,1,1,3,3,3hexafluoroisopropanol (HFIP) (99\%) was purchased from Aladdin reagent Co., Ltd (Shanghai, People's Republic of China). $\mathrm{CO}_{2}$ with a purity of $99.9 \%$ was supplied by Rihong Air Products Co., Ltd. (Xiamen, People's Republic of China).

The guinea pigs were supplied by the Slac Laboratory Animal Co., Ltd (Shanghai, People's Republic of China). 
The animals were acclimatized for 1 week prior to experiments. The temperature of the laboratory was maintained at $25^{\circ} \mathrm{C}$ and the animals were fed with water and chow ad libitum. All experiments were carried out in accordance with the guidelines issued by the Ethical Committee of Huaqiao University.

\section{Methods}

\section{Preparation of SF}

Silk powder was dissolved in a solution of calcium chloride, ethanol, and water $\left(\mathrm{CaCl}_{2}\right.$ :ethanol:water $=1: 2: 8$, molar ratio $)$ for 6 hours at $70^{\circ} \mathrm{C}$ to obtain the SF solution. Then, the pure SF solution was dialyzed in distilled water to remove the neutral salts using dialysis tube (MWCO 3500). The dry SF was obtained by lyophilizing for 48 hours with a freeze dryer.

\section{Preparation of $\mathrm{Fe}_{3} \mathrm{O}_{4}$-SF nanoparticles and MTX- $\mathrm{Fe}_{3} \mathrm{O}_{4}$-SF nanoparticles by SpEDS process}

An amount of magnetic fluid was suspended in DCM by ultrasonic dispersion while SF was dissolved in HFIP by magnetic stirring, and then the two solutions were mixed to form an $\mathrm{Fe}_{3} \mathrm{O}_{4}$ nanoparticle suspension in the polymer solution. Figure 1 shows the schematic diagram of the $\mathrm{SpEDS}$ process for preparation of $\mathrm{Fe}_{3} \mathrm{O}_{4}$-SF nanoparticles. During the experiment, the solution was delivered into the high-pressure vessel, where $\mathrm{CO}_{2}$ was present, via the inner route of the stainless steel coaxial nozzle at the rate of $0.5 \mathrm{~mL} \cdot \mathrm{min}^{-1}$. The pressure, temperature, and flow rate of $\mathrm{CO}_{2}$ were kept at $10 \mathrm{MPa}, 35^{\circ} \mathrm{C}$, and $1,500 \mathrm{~L} \cdot \mathrm{h}^{-1}$, respectively. When the spraying of the solution was finished, fresh $\mathrm{CO}_{2}$ was pumped in to wash the products for 30 minutes in order to remove the residual organic solvent. For the preparation of MTX-Fe ${ }_{3} \mathrm{O}_{4}$-SF nanoparticles, MTX was dissolved with SF in HFIP and mixed with an $\mathrm{Fe}_{3} \mathrm{O}_{4}$ nanoparticle suspension in DCM. The operating conditions were as described above.

\section{Surface morphology and particle size characterizations}

The surface morphology of the nanoparticles was observed by field-emission scanning electron microscope (S-4800; Hitachi Ltd., Tokyo, Japan). The samples were adhered onto the conducting resin and then coated with gold under vacuum conditions. The particle size and the particle size distribution of the nanoparticles was measured by Nano-measure from the scanning electron microscope photographs. The particle sizes of 300 particles were analyzed.

\section{Drug load and encapsulation efficiency}

In this study, the drug load (DL) was defined as the total content of the drug in the nanoparticles, and the encapsulation efficiency (EE) was defined as the percentage of the drug loaded in the nanoparticles. In order to determine the DL and $\mathrm{EE}$, approximately $10 \mathrm{mg}$ of $\mathrm{MTX}-\mathrm{Fe}_{3} \mathrm{O}_{4}-\mathrm{SF}$ nanoparticles, accurately weighed, was dissolved in $100 \mathrm{~mL}$ of phosphatebuffered saline (PBS) of $\mathrm{pH}$ 7.4. The amount of MTX was analyzed using an ultraviolet spectrophotometer (UV-2800; Unico Instrument Co., Ltd., Shanghai, People's Republic of China) at $302 \mathrm{~nm}$. The DL and EE were calculated by Equations 1 and 2, respectively:

$$
\mathrm{DL}=W_{1} / W_{2} \times 100 \%
$$

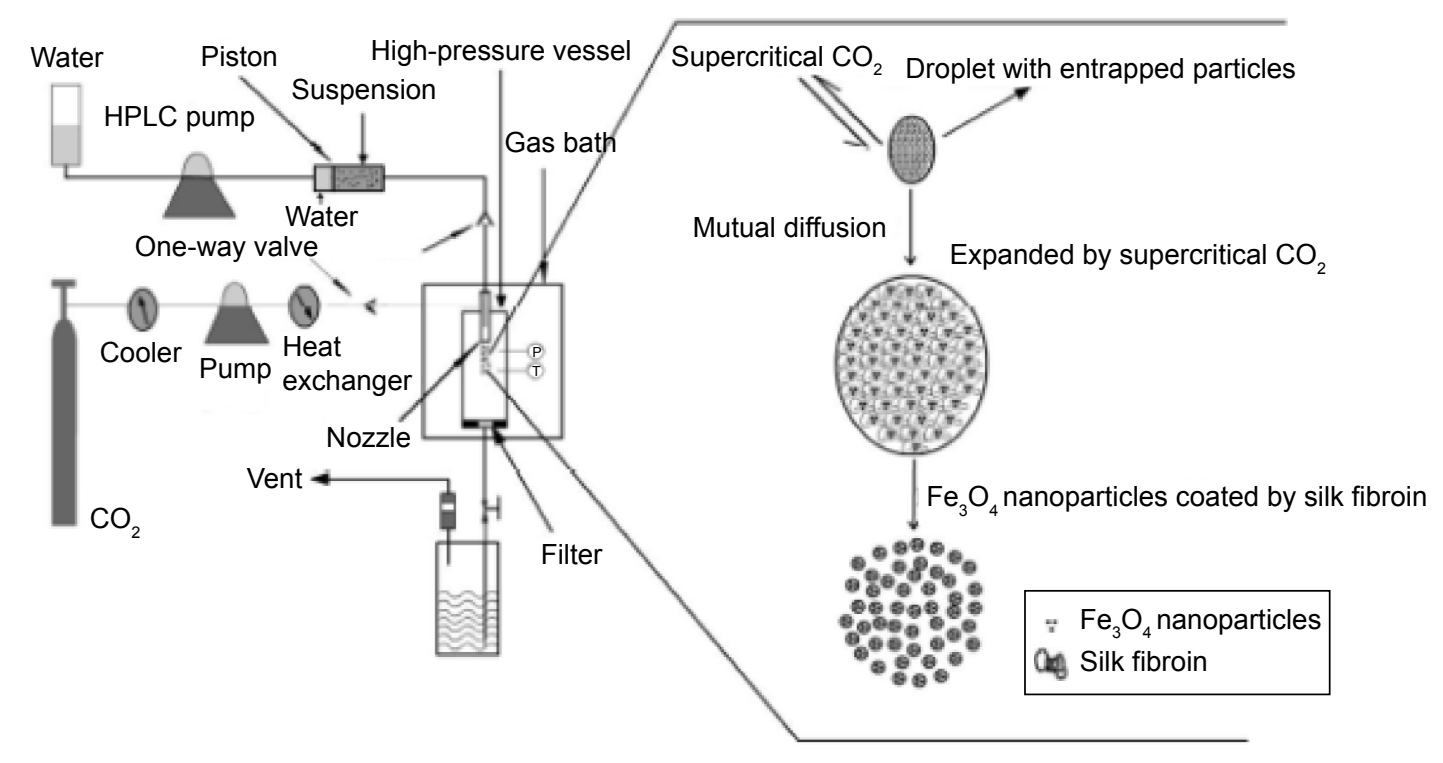

Figure I Schematic diagram for preparation of the $\mathrm{Fe}_{3} \mathrm{O}_{4}$-SF nanoparticles. 


$$
\mathrm{EE}=W_{1} / W_{3} \times 100 \%
$$

where $W_{1}$ is the weight of actual MTX in the MTX-Fe $\mathrm{O}_{4}-\mathrm{SF}$ nanoparticles, $W_{2}$ is the gross weight of the MTX- $\mathrm{Fe}_{3} \mathrm{O}_{4}-\mathrm{SF}$ nanoparticles, and $W_{3}$ is the weight of theoretical MTX in the MTX-Fe $\mathrm{O}_{4}$-SF nanoparticles.

\section{Skin preparation}

The guinea pig was killed by using an overdose of pentobarbital sodium. The hairs on the dorsal side were removed by a baby hair clipper, and the skin was excised from the guinea pig. Subsequently, the skin was washed with PBS (pH 7.4) and the dermal site was wiped with a cotton swab dipped in isopropyl alcohol to remove the adhering fats; ${ }^{9}$ the skin was then wrapped in aluminum foil and stored at $-20^{\circ} \mathrm{C}$.

\section{Passive drug permeation studies}

According to the previous studies, ${ }^{7,11,41}$ the skin permeation studies were performed using a Franz diffusion cell with 12 units which have an effective diffusion surface of $1.766 \mathrm{~cm}^{2}$ and a receptor compartment volume of $7 \mathrm{~mL}$. Prior to the experiment, the frozen skin was thawed at room temperature and mounted in the diffusion cell with the SC facing the donor compartment. The donor compartment was equilibrated with the receiver compartment solution PBS (pH 7.4) and stirred at $300 \mathrm{rpm}$ for 1 hour to accelerate skin hydration. One milliliter of nanoparticle formulation with the concentration of $1.0 \mathrm{mg} / \mathrm{mL}$ was applied on the surface of the skin in the donor compartment. The skin permeation studies were performed at $37^{\circ} \mathrm{C} \pm 1^{\circ} \mathrm{C}$ which was closer to the physiological condition. During the permeation studies, $400 \mu \mathrm{L}$ of the receiver compartment solution was sampled out at the sampling time points $(1,2,3,4,6$, and 8 hours) and replaced with fresh PBS of equal temperature and volume.
The accumulative permeated flux of MTX at different time intervals was analyzed by HPLC.

\section{Magnetophoretic skin permeation studies}

For the experiment to investigate the enhancement of penetration, the experimental setup was similar to that for passive drug permeation. As shown in Figure 2A, the stationary magnetic field was created by placing a neodymium magnet $(1.0 \mathrm{~cm}$ length $\times 0.6 \mathrm{~cm}$ width $\times 0.1 \mathrm{~cm}$ thickness) on both sides of the donor compartment at a distance of $5 \mathrm{~mm}$ under the skin, thus generating a driving force for the magnetic nanoparticles in a vertical direction toward the skin. The magnetic field strength at the skin surface was approximately $3 \mathrm{mT}$. Figure 2B shows the experimental setup under an alternating magnetic field: the coil was placed around the exterior of the donor compartment of the diffusion cell to drive the magnetic nanoparticles to have alternating movements on the skin in horizontal directions. The strength of the alternating magnetic field at the skin surface was approximately $3 \mathrm{mT}$. The stationary/alternating magnetic field is demonstrated in Figure 2C: the neodymium magnets and the coil were applied together on the diffusion cell to achieve driving forces for the magnetic nanoparticles in both horizontal and vertical directions. The permeation studies were carried out for 8 hours under different magnetic fields. For the passive permeation studies, the amount of MTX that permeated across skin into the receiver compartment solution was determined.

\section{HPLC analysis}

HPLC system (Shimadzu, Kyoto, Japan) performed with reverse phase $\mathrm{C} 18$ analytical column $(5 \mu \mathrm{m}, 250 \times 4.6 \mathrm{~mm})$ was used to analyze MTX. The mobile phase was $3 \%$ glacial acetic acid and acetonitrile of 90:10 (v/v) with a flow rate of $1.0 \mathrm{~mL} \cdot \mathrm{min}^{-1}$ using an injection volume of $20 \mu \mathrm{L}$. For
A

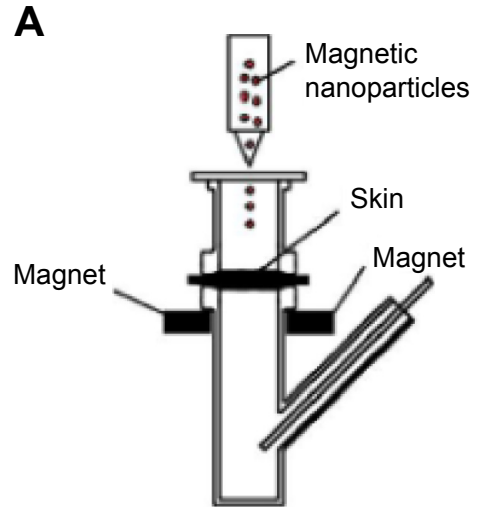

B

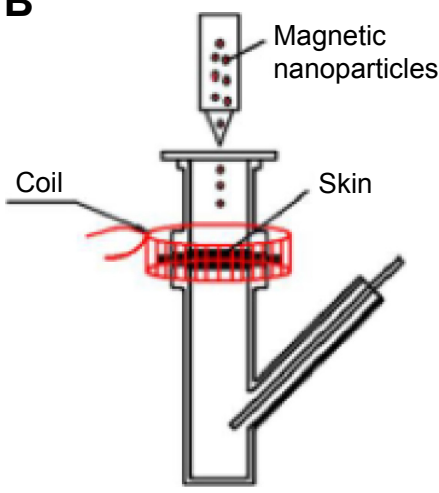

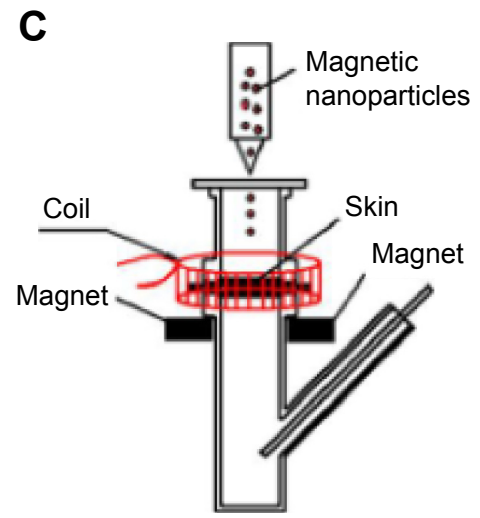

Figure 2 The experimental setup for permeation studies.

Notes: (A) Diffusion cell with stationary magnetic field; (B) diffusion cell with alternating magnetic field; and (C) diffusion cell with stationary/alternating magnetic fields. 
the calibration curves, a series of standard MTX solutions ranging from 0.1 to $20 \mu \mathrm{g} \cdot \mathrm{mL}^{-1}$ were prepared and analyzed. MTX content in the samples was determined at $302 \mathrm{~nm}$. Then, the peak area was subjected to the regression analysis for quantification.

\section{CLSM}

In order to investigate the nanoparticles' penetration across the skin, the fluorescent dye-loaded nanoparticles were used for CLSM studies. ${ }^{11,42}$ In the present study, the skin permeation studies with FITC-Fe $\mathrm{O}_{4}-\mathrm{SF}$ nanoparticles with or without magnetic field were performed. Briefly, the dosages were applied to the skin in the donor compartment of Franz diffusion cells and the receiver compartment was filled with PBS ( $\mathrm{pH}$ 7.4). After the permeation studies, the collected samples were embedded in optimum cutting temperature compound. Thin lateral serial skin sections were collected using cryotome (Leica CM1950; Leica Microsystems, Wetzlar, Germany). Then skin sections were visualized with a confocal laser scanning microscope (CarlZeiss LSM710; Carl Zeiss Meditec AG, Jena, Germany) using 10× objective. Finally, the collected images were analyzed for the skin distribution of fluorescence.

\section{ATR-FTIR analysis}

The preparation of skin was described as above, and then the following treatments were applied: 1) no treatment (control); 2) application of stationary magnetic field; 3) application of alternating magnetic field; and 4) application of stationary/ alternating magnetic field. After treatment, the skin sample was washed and scrubbed using cotton swab. Then, the resultant skin was obtained by vacuum drying at $37^{\circ} \mathrm{C}$ and stored at $4^{\circ} \mathrm{C}$ until analysis.

ATR-FTIR analysis of the skin samples was performed using a NicoletiS10 spectrometer from 4,000 to $400 \mathrm{~cm}^{-1}$ at a resolution of $4 \mathrm{~cm}^{-1}$ with 64 scans at room temperature. During the measurements, the SC of the skin samples was placed facing down on the ATR crystal of an ATR-FTIR spectrometer.

\section{Histopathological analysis}

The skin was paraffin-embedded, and hematoxylin-eosin stained for microstructure analysis using microscope.

\section{Statistical analysis}

All data are reported as the mean \pm standard deviation. The significant differences between the groups was carried out using SPSS for one-way analysis of variance.

\section{Results and discussion Characterization of the nanoparticles}

In a SpEDS process to prepare magnetic SF nanoparticles, the $\mathrm{Fe}_{3} \mathrm{O}_{4}$ nanoparticle suspension in SF solution was delivered through the inner part of the nozzle and sprayed together with supercritical $\mathrm{CO}_{2}$ through the external route into the high-pressure vessel; droplets were generated by the "spray enhancer" through the mechanical effects of supercritical $\mathrm{CO}_{2}$. When the droplets of solution contacted the supercritical $\mathrm{CO}_{2}$, fast mutual diffusion occurred and the droplet was expanded by the supercritical $\mathrm{CO}_{2}$; when the polymer solution approached a spontaneous supersaturation due to the extraction of HFIP from the droplet, SF was precipitated on the surface of the $\mathrm{Fe}_{3} \mathrm{O}_{4}$ nanoparticles.

Figure S1A-D of the supplementary materials shows the surface morphologies of $\mathrm{Fe}_{3} \mathrm{O}_{4}$-SF nanoparticles prepared with different $\mathrm{SF} / \mathrm{Fe}_{3} \mathrm{O}_{4}$ ratios of $40: 3,20: 3,10: 3$, and 5:3, respectively. When the ratio of $\mathrm{SF} / \mathrm{Fe}_{3} \mathrm{O}_{4}$ was $20: 3$, the $\mathrm{Fe}_{3} \mathrm{O}_{4}$-SF nanoparticles had a smooth surface, a spherical shape, and uniform particle size.

Figure 3 shows the surface morphologies of: 1) $\mathrm{Fe}_{3} \mathrm{O}_{4}-\mathrm{SF}$ nanoparticles prepared with $\mathrm{SF} / \mathrm{Fe}_{3} \mathrm{O}_{4}$ in a ratio of $20: 3$ and 2) $\mathrm{MTX}-\mathrm{Fe}_{3} \mathrm{O}_{4}-\mathrm{SF}$ nanoparticles with a DL of $20 \%$. The resulting $\mathrm{Fe}_{3} \mathrm{O}_{4}$-SF nanoparticles had a spherical shape, a smooth surface, a narrow size distribution, and a mean particle size of $112 \mathrm{~nm}$ (Figure S2A). The MTX-Fe $\mathrm{O}_{4}-\mathrm{SF}$ nanoparticles exhibited a mean particle size of $75 \mathrm{~nm}$ and a narrow size distribution (Figure S2B). As shown in the scanning electron microscope images, the composite magnetic SF nanoparticles had a tendency to aggregate together. It has been reported that particle aggregates produced by the supercritical fluid-based antisolvent process were disconnected. ${ }^{43}$ This may be caused by the small particle size and the surface activity of high reunion. ${ }^{44}$ However, these aggregates can be separated into the form of free nanoparticles when the powder is dispersed by ultrasonication. ${ }^{43}$ Gocmez et al ${ }^{45}$ also demonstrated that supercritical $\mathrm{CO}_{2}$ can be used to synthesize soft-agglomerated nanocrystalline powders, and the soft agglomeration generated with a hierarchical cluster-cluster agglomeration can be monodispersed under shear. ${ }^{46}$

The decrease in the mean particle size revealed that the addition of MTX accelerates the precipitation of the SF and MTX onto the $\mathrm{Fe}_{3} \mathrm{O}_{4}$ nanoparticles, thus generating smaller composite particles. It has been reported that with higher initial concentrations, smaller particles are obtained. This would be consistent with the higher supersaturation achieved with a higher initial concentration. ${ }^{47} \mathrm{Tu}$ et $\mathrm{al}^{48}$ explained that the concentration effect is in concordance with conventional 

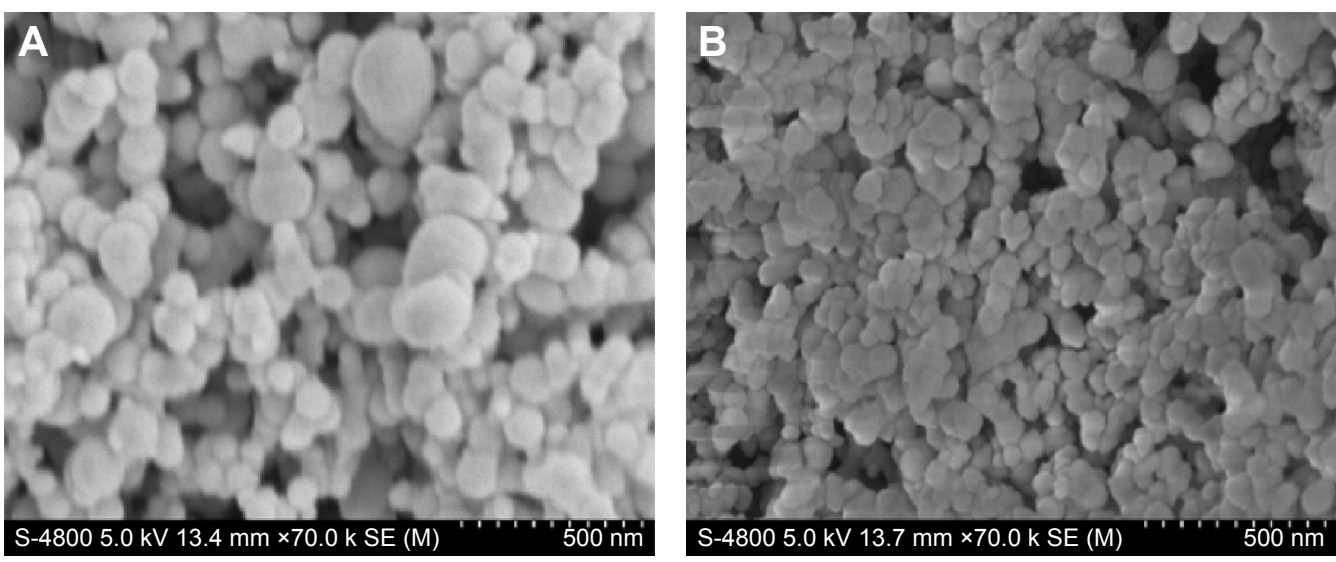

Figure 3 SEM photographs of nanoparticles.

Notes: (A) $\mathrm{Fe}_{3} \mathrm{O}_{4}-\mathrm{SF}$ nanoparticles with an $\mathrm{Fe}_{3} \mathrm{O}_{4}$ /SF ratio of 3:20; (B) MTX-Fe $\mathrm{O}_{4}$-SF nanoparticles (drug load =20\%).

Abbreviations: MTX, methotrexate; SEM, scanning electron microscope; SF, silk fibroin.

crystallization theory, which is based on the concept of solution supersaturation levels being the driving force for precipitation: a solution of a higher concentration reaches supersaturation faster than a less concentrated solution. As a result, there are higher nucleation rates and, therefore, smaller particles are precipitated from a more concentrated solution. Furthermore, DCM was used as nonsolvent for MTX. It was reported that the addition of miscible nonsolvent greatly decreased the solubility in the liquid phase which generated a higher saturation ratio of the solution without increasing the concentration. Thus, the supersaturation occurred more rapidly at a higher level in the supercritical process, and the resulting higher supersaturation ratio produced a much larger number of smaller particles. ${ }^{49}$

In the present study, the $\mathrm{Fe}_{3} \mathrm{O}_{4}$ nanoparticles acted as a crystal nucleus during the SpEDS process; the MTX could easily be crystallized and precipitated on the surface of $\mathrm{Fe}_{3} \mathrm{O}_{4}$ nanoparticles; and this also accelerates the precipitation of the SF, thus generating smaller composite particles.

\section{$\mathrm{DL}$ and $\mathrm{EE}$}

Figure 4 illustrates the DL and EE of MTX-loaded $\mathrm{Fe}_{3} \mathrm{O}_{4}-\mathrm{SF}$ nanoparticles. It was found that the measured DL increased with the increase in drug dosage, while the opposite phenomenon was observed for the EE. When theoretical DLs were set at $10 \%, 20 \%$, and $30 \%$, the corresponding DLs were $9.93 \% \pm 0.06 \%, 18.94 \% \pm 0.4 \%$, and $24.37 \% \pm 0.73 \%$, respectively, and their EEs were $99.29 \% \pm 0.57 \%, 94.72 \% \pm 2.01 \%$, and $81.24 \% \pm 2.43 \%$, respectively. It can be explained that $\mathrm{Fe}_{3} \mathrm{O}_{4}$ nanoparticles acted as a crystal nucleus during the SpEDS process. MTX had quite a low solubility in $\mathrm{CO}_{2}$ and could easily be coprecipitated with polymers on $\mathrm{Fe}_{3} \mathrm{O}_{4}$ nanoparticles, so the resulting DL was relatively high. The increase of drug loading, which exceeded the load capacity, leads to the decrease of EE; thus, the higher drug dosage would generate nanoparticles with a higher DL and a lower EE.

\section{In vitro permeation study of MTX by magnetophoresis}

The permeation of MTX through the skin from a solution was performed compared to the $\mathrm{MTX}-\mathrm{Fe}_{3} \mathrm{O}_{4}$-SF nanoparticles suspension in our pre-experiments. The result (Table S1) indicated that the MTX-Fe ${ }_{3} \mathrm{O}_{4}$-SF nanoparticles can effectively improve the drug permeation across the skin with an enhancement factor of 2.78, when compared to the MTX solution. Therefore, in this study, using the nanoparticles without magnetic field as the control, the comparison study

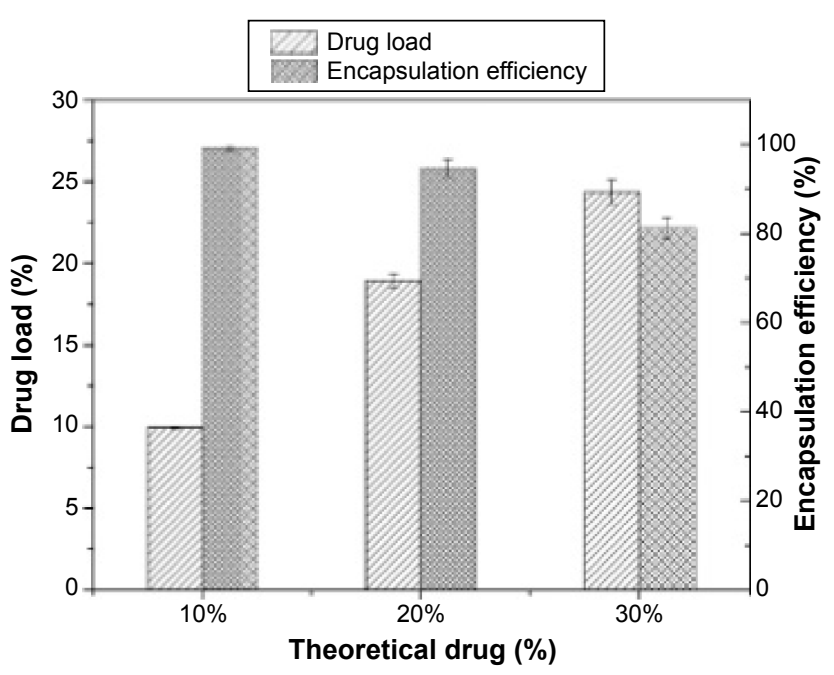

Figure 4 Drug load and encapsulation efficiency of $\mathrm{MTX}-\mathrm{Fe}_{3} \mathrm{O}_{4}$-SF nanoparticles. Abbreviations: MTX, methotrexate; SF, silk fibroin. 
on the cumulative amount of MTX penetrating the skin to the receptor compartment was carried out for the passive and magnetic field-induced transdermal drug deliveries. The data shown in Figure 5 clearly demonstrated the capability of the magnetic field to enhance the percutaneous delivery of MTX: the application of different kinds of magnetic fields all obtained a higher cumulative amount of MTX penetration than the passive administration. Meanwhile, the permeation flux enhancement factor $\left(E_{f}\right)$ was found to increase gradually when employing a stationary magnetic field, an alternating magnetic field, and a stationary/alternating magnetic field the $\mathrm{E}_{\mathrm{f}}$ being the comparison of permeation fluxes between the presence and absence of magnetic fields. The strategy of exploiting the magnetic field to enhance the percutaneous delivery of drugs originated from the assumption that the diamagnetic substances are repelled away from the magnetic field and then driven across the skin. However, the presence of a stationary magnetic field with an intensity of $3 \mathrm{mT}$ did not significantly increase the permeation of MTX, while the alternating magnetic field enhanced the permeation of MTX across the skin much more effectively than the stationary magnetic field $(P<0.05)$. This reveals that the driving force in the horizontal direction for the drug-loaded magnetic nanoparticles is more favorable for the permeation of MTX across the skin than the driving force in the vertical direction. Importantly, the combination of stationary and alternating magnetic fields, which can generate a massage-like driving force in both horizontal and vertical directions, achieved the best enhancement for the permeation of MTX across the skin $(P<0.01)$. We hypothesized that the mechanism of the alternating magnetic field improving the drug penetration is not based on magnetokinesis but the effects on the lipid transition of skin and the movement of the magnetic nanoparticles on the surface of skin, thus increasing the follicular transport. ${ }^{50}$ The combination of stationary and alternating magnetic fields achieves a synergistic effect to enhance the drug permeation via the simulated massage of the skin.

\section{CLSM}

The precise mechanism of permeation enhancement under an alternating magnetic field is presently poorly understood. In this study, we attempted to investigate the primary mechanism for this massage-like transdermal drug-delivery system. Confocal microscopy, a rapid and sensitive imaging technique, was widely used to analyze the distribution of fluorescence. The CLSM images provided qualitative information regarding the profile and depth of nanoparticles' penetration into skin to determine the distribution of the nanoparticles, thus investigating the possible pathway of permeation, which was in correlation with the possible mechanism. Lopez et $\mathrm{a}^{16}$ used the confocal microscopy to observe the penetration of Quantum dots into the SC and

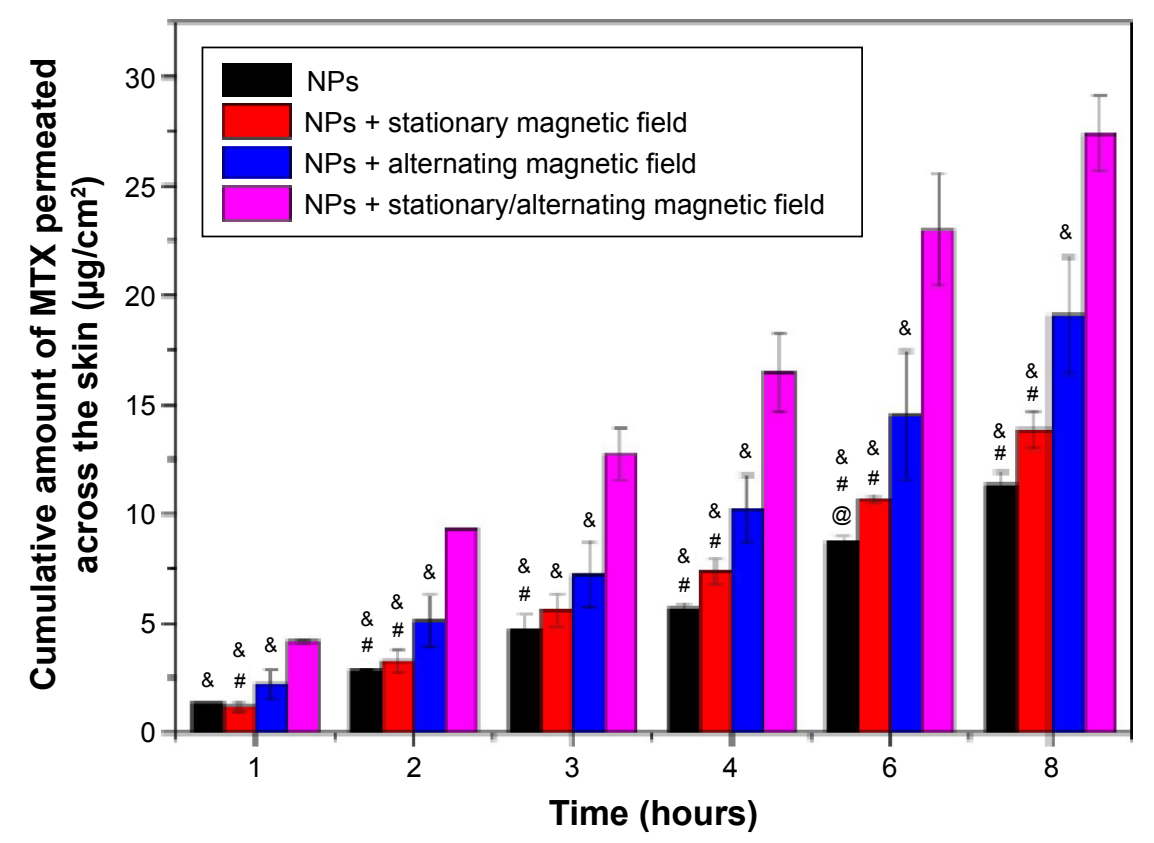

Figure $\mathbf{5}$ The cumulative permeation of MTX across the skin.

Notes: @, \#, and \& indicate the statistical significant difference when compared with the stationary magnetic field, the alternating magnetic field, and the stationary/ alternating magnetic field, respectively. $P<0.05$.

Abbreviations: MTX, methotrexate; NPs, nanoparticles. 
the dermis to supply qualitative information. Wang et $\mathrm{al}^{51}$ used the CLSM technique to evaluate the penetration depth of different formulations in skin and found that it was in accordance with the results obtained from in vitro permeation studies. Lee et $\mathrm{al}^{52}$ investigated the effects of $\mathrm{ZnO}$ nanoparticles on human keratinocyte cells by observing the absorption and localization of nanoparticles in cytoplasm and nuclei revealed by CLSM.

In this study, the FITC-labeled $\mathrm{Fe}_{3} \mathrm{O}_{4}$-SF nanoparticles were applied to the skin in the donor compartment of the Franz diffusion cell. The thin lateral serial skin sections were collected using a cryotome and then visualized with a confocal laser scanning microscope. Figure 6A-D shows the laser scanning microscope images of the penetration of FITC-Fe $\mathrm{O}_{4}$-SF nanoparticles under different magnetic fields. It was found that the stationary magnetic field generated a stronger fluorescence signal than the control group without any magnetic field, which means that more of the drug penetrated across the skin. In the case of the alternating magnetic field, it seems that a longer depth of fluorescence was detected in Figure 6C, while a larger area of the fluorescence under a stationary/alternating magnetic field in Figure 6D was observed at a similar depth to that of Figure $6 \mathrm{C}$. This bigger area might make a dominant contribution to the results of drug permeation, which means that the combination of stationary and alternating magnetic fields can greatly enhance the drug penetration, and this was supported by the results of in vitro permeation studies by HPLC analysis. It is suggested that the alternating magnetic field can drive the movement of magnetic nanoparticles on the surface of the skin, thus enhancing the follicular penetration; combination with a stationary magnetic field produces an enhanced massage-like effect on the skin which further induces the drug permeation across the skin. This finding is in agreement with the recent investigations which have revealed that the pumping effect of the moving hairs could enhance drug permeation. ${ }^{53}$ The movement of hairs is a physiological process, but it must be stimulated by something, such as manual massage. Trauer et $\mathrm{al}^{28}$ concluded that the fluorescence signal could penetrate a deeper region of the hair follicles with massage, which stimulates the follicular penetration. Lademann et $\mathrm{al}^{27}$ also demonstrated a comparable increase in follicular penetration
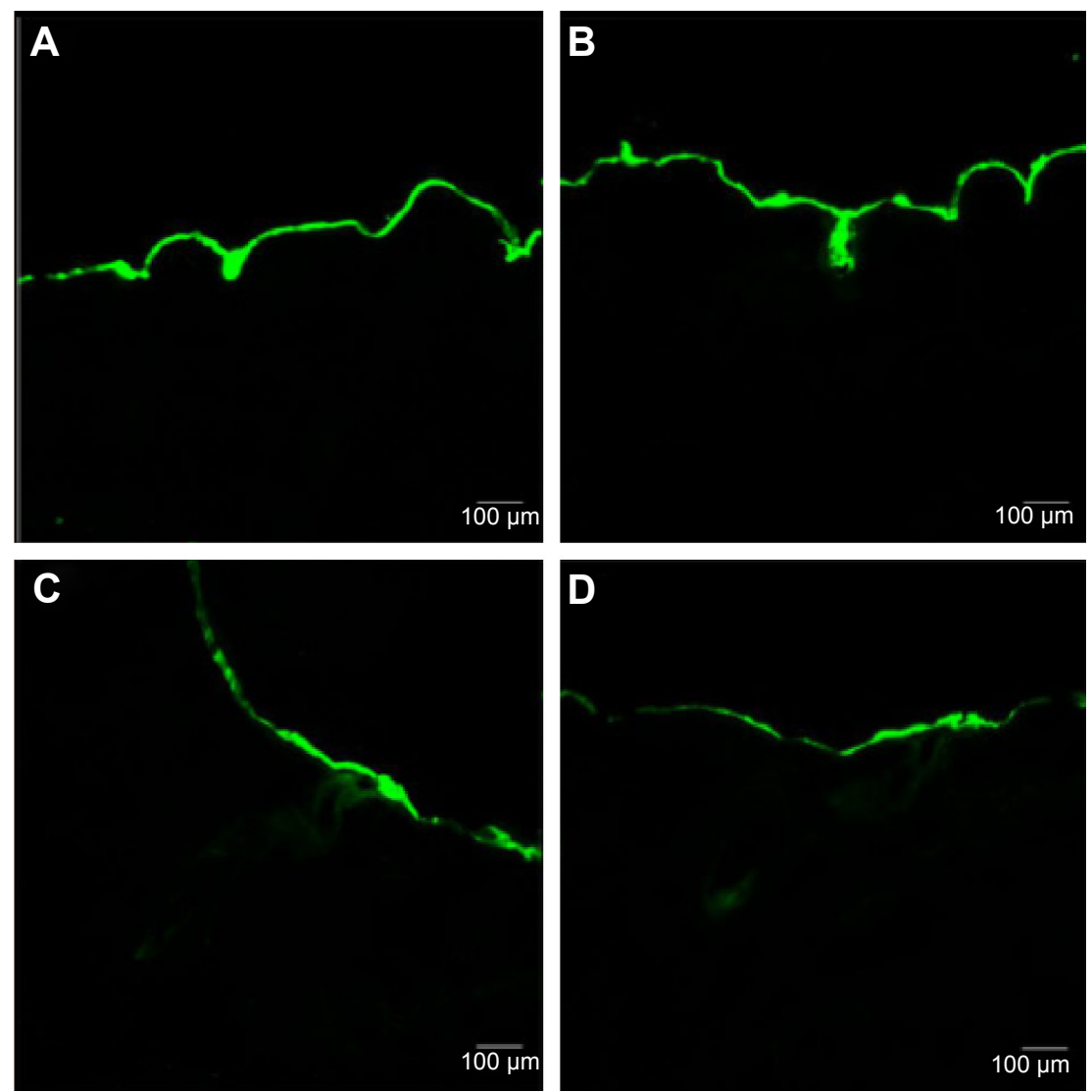

Figure 6 Laser scanning microscope images of the penetration of FITC-Fe $\mathrm{O}_{4}$-SF nanoparticles.

Notes: (A) Control; (B) stationary magnetic field; (C) alternating magnetic field; and (D) stationary/alternating magnetic fields.

Abbreviations: FITC, fluorescein isothiocyanate; SF, silk fibroin. 
depth - the penetration of particles being enhanced by mechanical massage.

\section{ATR-FTIR spectroscopy}

ATR-FTIR spectroscopy was also performed to observe the skin under different conditions, since it is a noninvasive technique for characterization of the SC at a molecular level directly, without any further treatments. The skin bands obtained from skin intercellular lipids and keratin (corneocytes) were as follows: the modes were associated with protein as amide $\mathrm{I}(\mathrm{C}=\mathrm{O})$ vibration (at approximately $1,640 \mathrm{~cm}^{-1}$ ) and amide II $(\mathrm{C}=\mathrm{N})$ (at approximately $1,540 \mathrm{~cm}^{-1}$ ) as well as with a stretching band from the fatty acids (at approximately $1,740 \mathrm{~cm}^{-1}$ ). The SC lipid bands at 2,800 and $3,000 \mathrm{~cm}^{-1}$ were due to the $\mathrm{CH}_{2}$ stretching vibrations, providing information about the conformational order-disorder transitions. The absorbencies for the asymmetric and symmetric stretching $\mathrm{CH}_{2}$ vibrations occurred near 2,920 and $2,850 \mathrm{~cm}^{-1}$. The scissoring vibrations provided information about the lateral packing of the lipids in the SC and the mode was between 1,470 and 1,460 $\mathrm{cm}^{-1} .{ }^{54,55}$ In Figure 7, it can be clearly seen that the skin subjected to a stationary magnetic field shows a similar spectrum to the control. However, after exposure to an alternating magnetic field, the symmetric and asymmetric methylene stretching bands were shifted to lower values as shown in Figure 7B. This result indicates that there was a lipid order-disorder transition from the gel to the lipid-crystalline state; ${ }^{56}$ a similar phenomenon was also observed in the group under stationary/alternating magnetic fields. Research has shown that this transition can increase the fluidity of the SC lipids, which could increase the skin penetration. ${ }^{57}$ This result suggests that the lipid transition caused by the alternating magnetic field is one of the predominant mechanisms responsible for the enhancement of drug permeation. However, the alternating magnetic field has no biological effect on the skin. As shown in Figure S3. The structure of the skin was intact in the case of the alternating magnetic field which was similar to the control. The SC was not separated from the skin epidermis but closely arranged on the epidermis; the adjacent SC and stratum spinosum was orderly and compactly arranged, and the inflammation tissue in the skin was hardly observed. This illustrates that the application of the alternating magnetic field has no sensitization or any other biological effect on the skin.

\section{Conclusion}

In conclusion, the application of magnetic fields has been shown to improve the penetration of drugs across the skin; an alternating magnetic field enhances the percutaneous penetration more effectively than a stationary type under the same intensity of field, and the combination of stationary and alternating magnetic fields achieves the best enhancement of drug permeation. The preliminary study on mechanisms in this work demonstrates that an alternating magnetic field can change the lipid order-disorder transition from the gel to the lipid-crystalline state, which increases the fluidity of the $\mathrm{SC}$ and thus enhances the drug penetration. The alternating magnetic field can also induce the movement of magnetic nanoparticles, which stimulates the movement of the hairs, leading to enhanced follicular penetration. Remarkably, the synergistic combination of stationary and alternating magnetic fields acting on the magnetic nanoparticles,
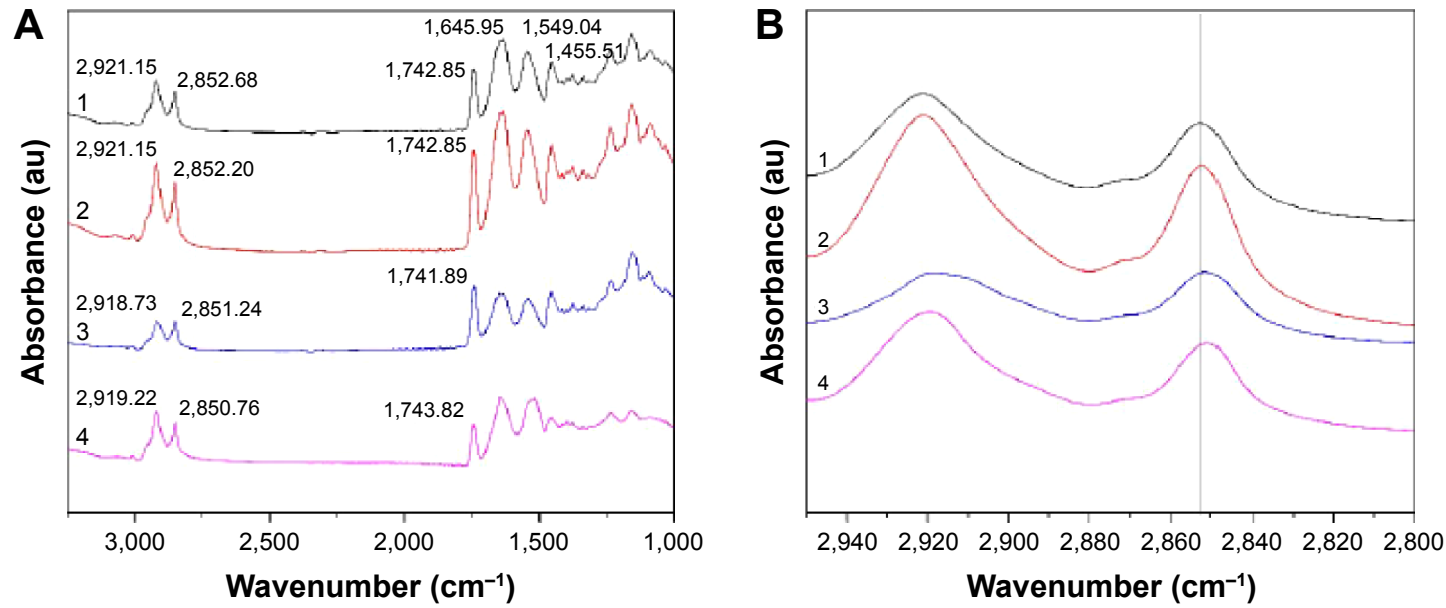

Figure 7 ATR-FTIR spectra of skin.

Notes: I: Control. 2: Stationary magnetic field. 3: Alternating magnetic field. 4: Stationary/alternating magnetic fields. (A) ATR-FTIR spectra of skin and (B) ATR-FTIR spectra of stratum corneum in the $\mathrm{C}-\mathrm{H}$ stretching region between 2,800 and $2,950 \mathrm{~cm}^{-1}$.

Abbreviation: ATR-FTIR, attenuated total reflection Fourier-transform infrared spectroscopy. 
which generates a massage-like effect on the skin, has great potential for enhancing the permeation of the drugs and agents that can be embedded with magnetic nanoparticles, which would greatly widen the application of transdermal drug-delivery systems.

\section{Acknowledgments}

Financial supports from National Natural Science Foundation of China (31470927 and 31170939 ), Natural Science Foundation of Fujian Province of China (2014J01128), Public Science and Technology Research Funds Projects of Ocean (201505029), and Promotion Program for Young and Middle-aged Teacher in Science and Technology Research of Huaqiao University (ZQN-PY107) are gratefully acknowledged.

\section{Disclosure}

The authors report no conflicts of interest in this work.

\section{References}

1. Prausnitz MR, Langer R. Transdermal drug delivery. Nat Biotechnol. 2008;26:1261-1268.

2. Alexander A, Dwivedi S, Ajazuddin, et al. Approaches for breaking the barriers of drug permeation through transdermal drug delivery. $J$ Control Release. 2012;164:26-40.

3. Li L, Zhang Y, Han S, et al. Penetration enhancement of lidocaine hydrochloride by a novel chitosan coated elastic liposome for transdermal drug delivery. J Biomed Nanotechnol. 2011;7:704-713.

4. Vitorino C, Almeida J, Gonçalves LM, Almeida AJ, Sousa JJ, Pais AA. Co-encapsulating nanostructured lipid carriers for transdermal application: from experimental design to the molecular detail. J Control Release. 2013;167:301-314.

5. Shen LN, Zhang YT, Wang Q, Xu L, Feng NP. Preparation and evaluation of microemulsion-based transdermal delivery of total flavone of rhizome arisaematis. Int J Nanomedicine. 2014;9:3453-3464.

6. Mahmood S, Taher M, Mandal UK. Experimental design and optimization of raloxifene hydrochloride loaded nanotransfersomes for transdermal application. Int J Nanomedicine. 2014;9: 4331-4346.

7. Santander-Ortega MJ, Stauner J, Loretz B, et al. Nanoparticles made from novel starch derivatives for transdermal drug delivery. $J$ Control Release. 2010;14:85-92.

8. Desai PR, Marepally S, Patel AR, Voshavar C, Chaudhuri A, Singh M. Topical delivery of anti-TNF $\alpha$ siRNA and capsaicin via novel lipidpolymer hybrid nanoparticles efficiently inhibits skin inflammation in vivo. J Control Release. 2013;170:51-63.

9. Hussain Z, Katas H, Mohd Amin MC, Kumolosasi E, Buang F, Sahudin S. Self-assembled polymeric nanoparticles for percutaneous co-delivery of hydrocortisone/hydroxytyrosol: an ex vivo and in vivo study using an NC/Nga mouse model. Int J Pharm. 2013;444:109-119.

10. Prow TW, Grice JE, Lin LL, et al. Nanoparticles and microparticles for skin drug delivery. Adv Drug Deliv Rev. 2011;63:470-491.

11. Shah PP, Desai PR, Singh M. Effect of oleic acid modified polymeric bilayered nanoparticles on percutaneous delivery of spantide II and ketoprofen. J Control Release. 2012;158:336-345.

12. Tomoda K, Terashima H, Suzuki K, Inagi T, Teradaand H, Makino K. Enhanced transdermal delivery of indomethacin using combination of PLGA nanoparticles and iontophoresis in vivo. Colloids Surf B Biointerfaces. 2012;92:50-54.
13. Park CH, Tijing LD, Kim CS, Lee KM. Needle-free transdermal delivery using PLGA nanoparticles: effect of particle size, injection pressure and syringe orifice diameter. Colloids Surf B Biointerfaces. 2014;123:710-715.

14. Tomoda K, Watanabe A, Suzuki K, Inagi T, Terada H, Makino K. Enhanced transdermal permeability of estradiol using combination of PLGA nanoparticles system and iontophoresis. Colloids Surf B Biointerfaces. 2012;97:84-89.

15. Zhang W, Gao J, Zhu Q, et al. Penetration and distribution of PLGA nanoparticles in the human skin treated with microneedles. Int J Pharm. 2010;402:205-212.

16. Lopez RF, Seto JE, Blankschtein D, Langer R. Enhancing the transdermal delivery of rigid nanoparticles using the simultaneous application of ultrasound and sodium lauryl sulfate. Biomaterials. 2011;32:933-941.

17. Ke CJ, Lin YJ, Hu YC, et al. Multidrug release based on microneedle arrays filled with $\mathrm{pH}$-responsive PLGA hollow microspheres. Biomaterials. 2012;33:5156-5165.

18. Murthy SN. Magnetophoresis: an approach to enhance transdermal drug diffusion. Pharmazie. 1999;54:377-379.

19. Murthy SN, Sammeta SM, Bowers C. Magnetophoresis for enhancing transdermal drug delivery: mechanistic studies and patch design. J Control Release. 2010;148:197-203.

20. Krishnan G, Edwards J, Chen Y, Benson HA. Enhanced skin permeation of naltrexone by pulsed electromagnetic fields in human skin in vitro. J Pharm Sci. 2010;99:2724-2731.

21. Namjoshi S, Chen Y, Edwards J, Benson HA. Enhanced transdermal delivery of a dipeptide by dermaportation. Biopolymers. 2008;90: 655-662.

22. Bassett CA. Beneficial effects of electromagnetic fields. J Cell Biochem. 1993;51:387-393.

23. Rancan F, Papakostas D, Hadam S, et al. Investigation of polylactic acid (PLA) nanoparticles as drug delivery systems for local dermatotherapy. Pharm Res. 2009;26:2027-2036.

24. Kimura E, Kawano Y, Todo H, Ikarashi Y, Sugibayashi K. Measurement of skin permeation/penetration of nanoparticles for their safety evaluation. Biol Pharm Bull. 2012;35:1476-1486.

25. Wosicka $\mathrm{H}, \mathrm{Cal} \mathrm{K}$. Targeting to the hair follicles: current status and potential. J Dermatol Sci. 2010;57:83-89.

26. Raber AS, Mittal A, Schäfer J, et al. Quantification of nanoparticle uptake into hair follicles in pig ear and human forearm. $J$ Control Release. 2014;179:25-32.

27. Lademann J, Richter H, Teichmann A, et al. Nanoparticles - an efficient carrier for drug delivery into the hair follicles. Eur J Pharm Biopharm. 2007;66:159-164.

28. Trauer S, Richter H, Kuntsche J, et al. Influence of massage and occlusion on the ex vivo skin penetration of rigid liposomes and invasomes. Eur J Pharm Biopharm. 2014;86:301-306.

29. Kwon TK, Lim KB, Kim JC. Solid lipid nanoparticles coated with silk fibroin. Journal of Industrial and Engineering Chemistry. 2011;17: $10-13$.

30. Shen Y, Redmond SL, Papadimitriou JM, et al. The biocompatibility of silk fibroin and acellular collagen scaffolds for tissue engineering in the ear. Biomed Mater. 2014;9:015015.

31. Kundu B, Kundu SC. Silk sericin/polyacrylamide in situ forming hydrogels for dermal reconstruction. Biomaterials. 2012;33:7456-7467.

32. Chen AZ, Li L, Wang SB, et al. Study of $\mathrm{Fe}_{3} \mathrm{O}_{4}-\mathrm{PLLA}-\mathrm{PEG}-\mathrm{PLLA}$ magnetic microspheres based on supercritical $\mathrm{CO}_{2}$ : Preparation, physicochemical characterization, and drug loading investigation. J Supercrit Fluids. 2012;67:139-148.

33. Chen AZ, Wang GY, Wang SB, Li L, Liu YG, Zhao C. Formation of methotrexate-PLLA-PEG-PLLA composite microspheres by microencapsulation through a process of suspension-enhanced dispersion by supercritical $\mathrm{CO}_{2}$. Int J Nanomedicine. 2012;7:3013-3022.

34. Stagni G, Shukla C. Pharmacokinetics of methotrexate in rabbit skin and plasma after iv-bolus and iontophoretic administrations. J Control Release. 2003;93:283-292. 
35. Hunter GA. The use of methotrexate in the treatment of psoriasis. Aust J Dermatol. 1962;6:248-254.

36. Hoffmeister RT. Methotrexate therapy in rheumatoid arthritis: 15 years experience. Am J Med. 1983;75:69-73.

37. Van Dooren-Greebe RJ, Kuijpers AL, Mulder J, De Boo T, Van de Kerkhof PC. Methotrexate revisited: effects of long term treatment in psoriasis. Br J Dermatol. 1994;130:204-210.

38. Alvarez-Figueroa MJ, Delgado-Charro MB, Blanco-Méndez J. Passive and iontophoretic transdermal penetration of methotrexate. Int J Pharm. 2001;212:101-107.

38. Alvarez-Figueroa MJ, Blanco-Méndez J. Transdermal delivery of methotrexate: iontophoretic delivery from hydrogels and passive delivery from microemulsions. Int J Pharm. 2001;215:57-65.

40. Javadzadeh Y, Hamishehkar H. Enhancing percutaneous delivery of methotrexate using different types of surfactants. Colloids Surf B Biointerfaces. 2011;82:422-426.

41. Gomes MJ, Martins S, Ferreira D, Segundo MA, Reis S. Lipid nanoparticles for topical and transdermal application for alopecia treatment: development, physicochemical characterization, and in vitro release and penetration studies. Int J Nanomedicine. 2014;9:1231-1242.

42. Patlolla RR, Desai PR, Belay K, Singh MS. Translocation of cell penetrating peptide engrafted nanoparticles across skin layers. Biomaterials. 2010; 31:5598-5607.

43. Torino E, De Marco I, Reverchon E. Organic nanoparticles recovery in supercritical antisolvent precipitation. J Supercrit Fluids. 2010;55: 300-306.

44. Zhao X, Chen X, Zu Y, Jiang R, Zhao D. Recrystallization and micronization of taxol using the supercritical antisolvent (SAS) process. Ind Eng Chem Res. 2012;51:9591-9597.

45. Gocmez H, Tuncer M, Uzulmez I. The preparation and characterization of soft-agglomerated $\mathrm{ZrO}_{2}-\mathrm{SiO}_{2}$ nanocrystalline composite by supercritical $\mathrm{CO}_{2}$. Ceram Int. 2010;36:2231-2234.

46. Eggersdorfer ML, Kadau D, Herrmann HJ, Pratsinis SE. Fragmentation and restructuring of soft-agglomerates under shear. J Colloid Interface Sci. 2010;342:261-268.

47. Chen AZ, Li L, Wang SB, et al. Nanonization of methotrexate by solution-enhanced dispersion by supercritical $\mathrm{CO}_{2} . J$ Supercrit Fluids. 2012;67:7-13.
48. Tu LS, Dehghani F, Foster NR. Micronisation and microencapsulation of pharmaceuticals using a carbon dioxide antisolvent. Powder Technology. 2002;126:134-149.

49. Chen AZ, Li Y, Chau FT, et al. Application of organic nonsolvent in the process of solution-enhanced dispersion by supercritical $\mathrm{CO}_{2}$ to prepare puerarin fine particles. J Supercrit Fluid. 2009;49:394-402.

50. Namjoshi S, Caccetta R, Edwards J, Benson HA. Liquid chromatography assay for 5-aminolevulinic acid: application to in vitro assessment of skin penetration via Dermaportation. J Chromatogr B Analyt Technol Biomed Life Sci. 2007;852:49-55.

51. Wang Y, Su WY, Li Q, et al. Preparation and evaluation of lidocaine hydrochloride-loaded TAT-conjugated polymeric liposomes for transdermal delivery. Int J Pharm. 2013;441:748-756.

52. Lee PL, Chen BC, Gollavelli G, et al. Development and validation of TOF-SIMS and CLSM imaging method for cytotoxicity study of $\mathrm{ZnO}$ nanoparticles in HaCaT cells. J Hazard Mater. 2014;277:3-12.

53. Lademann J, Patzelt A, Richter H, Antomiou C, Sterry W, Knorr F. Determination of the cuticula thickness of human and porcine hairs and their potential influence on the penetration of nanoparticles into the follicles. J Biomed Opt. 2009;14:021014.

54. Cilurzo F, Vistoli G, Selmin F, et al. An insight into the skin penetration enhancement mechanism of N-methylpyrrolidone. Mol Pharm. 2014;11:1014-1021.

55. Hoppel M, Baurecht D, Holper E, Mahrhauser D, Valenta C. Validation of the combined ATR-FTIR/tape stripping technique for monitoring the distribution of surfactants in the stratum corneum. Int $J$ Pharm. 2014;472:88-93.

56. Hasanovic A, Winkler R, Resch GP, Valenta C. Modification of the conformational skin structure by treatment with liposomal formulations and its correlation to the penetration depth of acyclovir. Eur J Pharm Biopharm. 2011;79:76-81.

57. Rodríguez G, Barbosa-Barros L, Rubio L, et al. Conformational changes in stratum corneum lipids by effect of bicellar systems. Langmuir. 2009;25:10595-10603. 


\section{Supplementary materials}
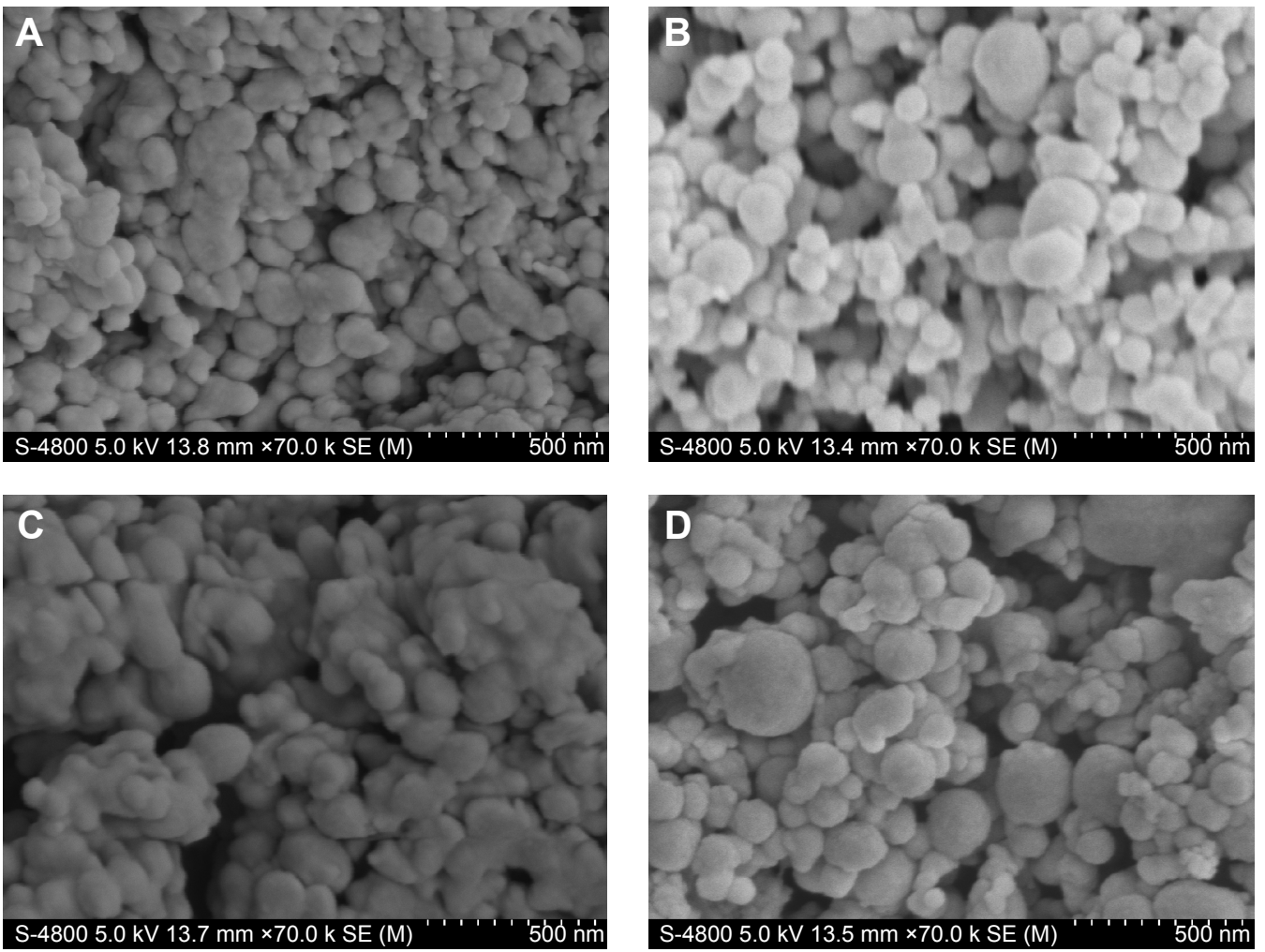

Figure SI SEM photographs of $\mathrm{Fe}_{3} \mathrm{O}_{4}$-SF nanoparticles in different ratios of $\mathrm{SF} / \mathrm{Fe}_{3} \mathrm{O}_{4}$. Notes: $\mathrm{SF} / \mathrm{Fe}_{3} \mathrm{O}_{4}=$ (A) 40:3; (B) 20:3; (C) 10:3; (D) 5:3.

Abbreviations: SEM, scanning electron microscope; SF, silk fibroin.
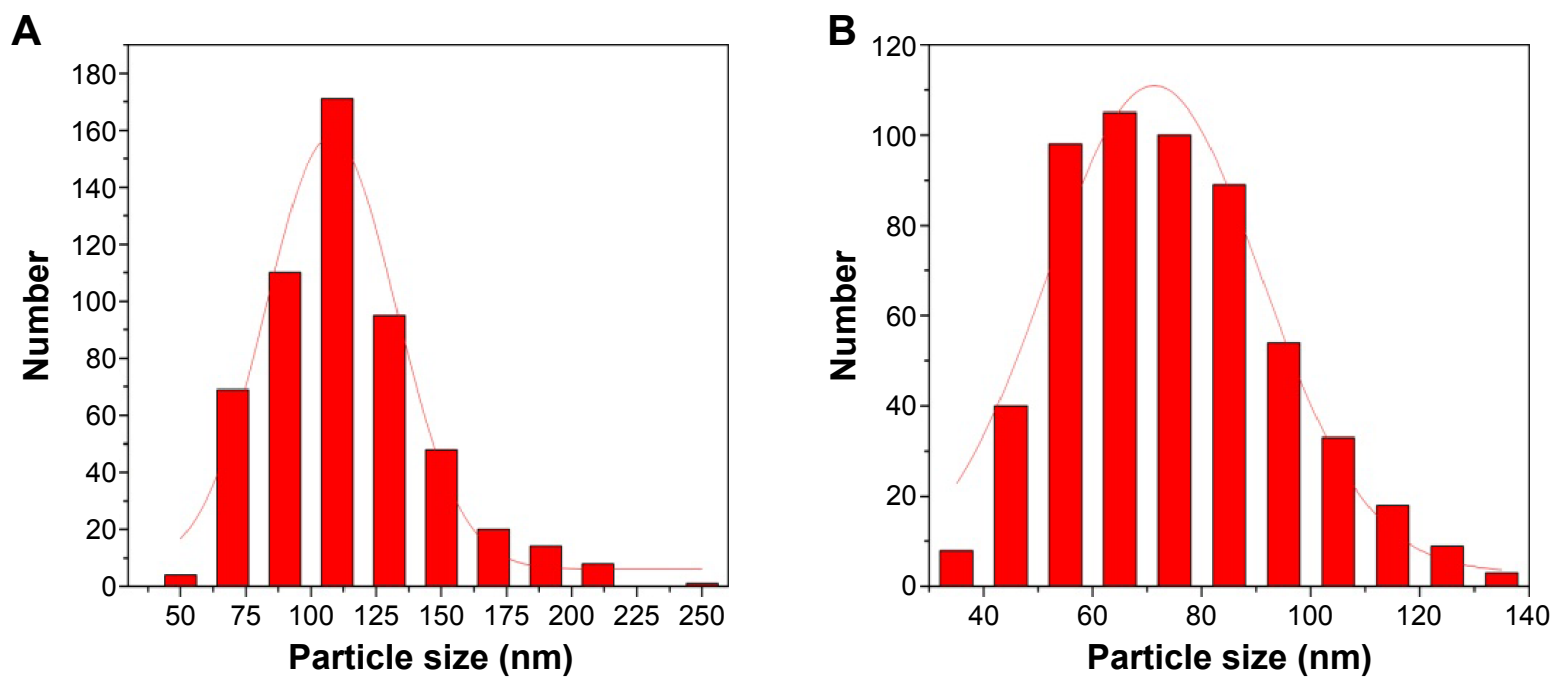

$\mathrm{SF} / \mathrm{Fe}_{3} \mathrm{O}_{4}=20: 3$

Figure S2 Particle size distribution.

Notes: (A) $\mathrm{Fe}_{3} \mathrm{O}_{4}$-SF nanoparticles $\left(\mathrm{SF} / \mathrm{Fe}_{3} \mathrm{O}_{4}=20: 3\right)$ and (B) MTX- $\mathrm{Fe}_{3} \mathrm{O}_{4}$-SF nanoparticles.

Abbreviations: MTX, methotrexate; SF, silk fibroin. 
Table SI Permeation coefficient of MTX solution and MTX- $\mathrm{Fe}_{3} \mathrm{O}_{4}-\mathrm{SF} \mathrm{NPs}$

\begin{tabular}{|c|c|c|c|}
\hline & $\begin{array}{l}\text { Steady-state flux } \\
\text { Js }\left(\mu \mathrm{g} \cdot \mathbf{h}^{-1} \cdot \mathbf{c m}^{-2}\right)\end{array}$ & $\begin{array}{l}\text { Permeability coefficient } \\
\text { Kp }\left(10^{-3} \cdot \mathrm{cm} \cdot \mathrm{h}^{-1}\right)\end{array}$ & $\begin{array}{l}\text { Enhancement } \\
\text { factor }\end{array}$ \\
\hline MTX solution & 1.66 & 8.32 & 1.00 \\
\hline $\mathrm{MTX}-\mathrm{Fe}_{3} \mathrm{O}_{4}-\mathrm{SF} \mathrm{NPS}$ & 2.87 & 14.33 & 2.78 \\
\hline
\end{tabular}

Abbreviations: MTX, methotrexate; NPs, nanoparticles; SF, silk fibroin.
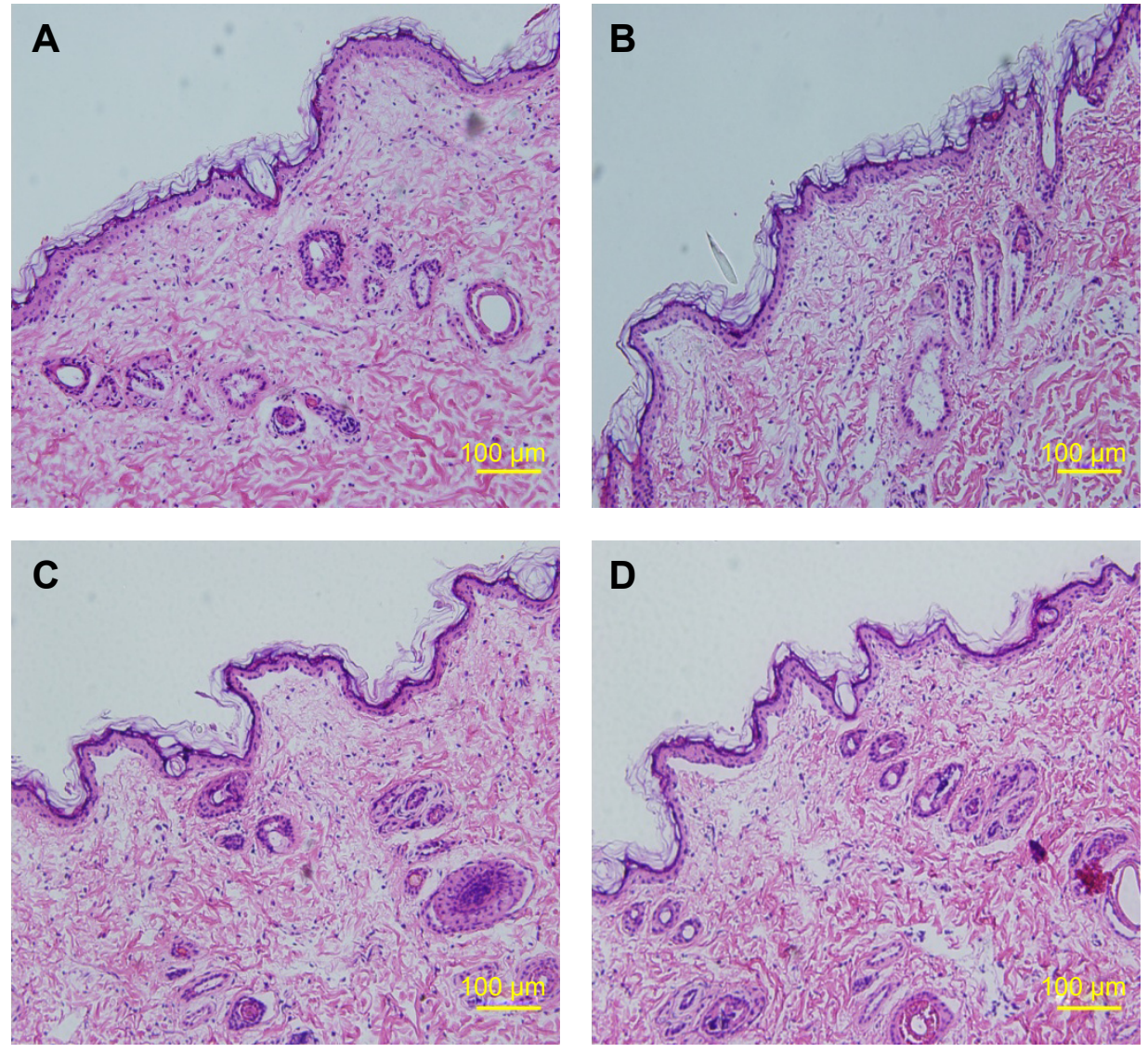

Figure S3 Histopathological analyses of skin.

Notes: (A) Control; (B) stationary magnetic field; (C) alternating magnetic field; and (D) stationary/alternating magnetic field.

International Journal of Nanomedicine

\section{Publish your work in this journal}

The International Journal of Nanomedicine is an international, peerreviewed journal focusing on the application of nanotechnology in diagnostics, therapeutics, and drug delivery systems throughou the biomedical field. This journal is indexed on PubMed Central, MedLine, CAS, SciSearch $\AA$, Current Contents ${ }^{\circledR} /$ Clinical Medicine,

\section{Dovepress}

Journal Citation Reports/Science Edition, EMBase, Scopus and the Elsevier Bibliographic databases. The manuscript management system is completely online and includes a very quick and fair peer-review system, which is all easy to use. Visit http://www.dovepress.com/ testimonials.php to read real quotes from published authors.

\footnotetext{
Submit your manuscript here: http://www.dovepress.com/international-journal-of-nanomedicine-journal
} 